\title{
Gender in the Adoption and Implementation of Sex Education Policy
}

\author{
Susanne N. Beechey ${ }^{1}$, Leah Curran Moon ${ }^{2}$ \\ ${ }^{1}$ Whitman College, Walla Walla, USA \\ ${ }^{2}$ Independent Scholar, Washington DC, USA \\ Email: beechesn@whitman.edu
}

Received 11 June 2015; accepted 11 July 2015; published 15 July 2015

Copyright (C) 2015 by authors and Scientific Research Publishing Inc.

This work is licensed under the Creative Commons Attribution International License (CC BY). http://creativecommons.org/licenses/by/4.0/

(c) (i) Open Access

\begin{abstract}
We contribute to the study of gender in the US federal policymaking process by charting the relationship between the gendered meanings mobilized in the congressional debate over abstinenceonly sex education policy and the gendered meanings produced within the implemented curricula. We find that abstinence-only sex education programs were rationalized in gender neutral terms in Congress while celebrating gender difference and producing explicitly gendered meanings in implementation. This contradiction between the gender neutrality of the congressional debates and the highly gendered lessons of the curricula raises important questions for how gender functions across the policy process. The argument of "what works", abstinence or comprehension, is not enough; we need to pay attention to how it works, especially with regard to the teaching of gender inequality.
\end{abstract}

\section{Keywords}

Sex Education, Abstinence, Gender, Congress, Implementation

\section{Introduction}

In addition to providing benefits and burdens, public policies also produce meanings, yet in the study of the public policy process, the construction and mobilization of gendered meanings remain understudied [1] [2]. Anne Schneider and Helen Ingram highlight the importance of studying the meanings conveyed through public policy when they state:

Policy affects citizens in many ways, most strikingly through the messages it imparts, both instrumental and symbolic. Through instrumental effects it shapes the distribution of valued goods and services. Through rhetorical claims attached to material policy, as well as that which is purely symbolic, policy sig- 
nals who is important. The result is unequal citizenship [3].

Both policy adoption and implementation are important sites for the study of policy meaning as Dvora Yanow argues, "A close match between policy intentions and agency outcomes is the exception rather than the rule [4]."

We seek to contribute to the study of gender in the US federal policymaking process by charting the relationship between the gendered meanings mobilized in the congressional debate over abstinence-only sex education policy and the gendered meanings produced within the implemented curricula. We find that while the curricula themselves actively teach and celebrate gender difference, the congressional debates occur in almost exclusively gender neutral terms. Abstinence-only sex education programs were rationalized in gender neutral terms in Congress while producing explicitly gendered meanings in implementation.

\section{Sex Education Policy Debates}

Sex education has long been a contentious policy area at the local level with debates raging on school boards since the mid-1960s [5]. In the 1990s hundreds of sex education controversies occurred on local school boards [6] [7]. During this time on the federal level abstinence-only policymaking functioned as "stealth morality politics" as funding was quietly attached to the 1996 welfare reform with little public debate [8]. Abstinence-only education (AOE) is sex education targeted at teenagers that aims to delay the initiation of sexual activity until heterosexual marriage while encouraging sexually active teens to return to abstinence until they marry. AOE programs teach that abstinence from sexual activity until heterosexual marriage is the expected standard for all human sexual activity. They do not teach about disease prevention or contraception, except in terms of failure rates. Federal support for abstinence-only education in the United States reached its peak during the George W. Bush Administration, as the federal and state governments spent over \$1.5 billion on AOE between 1998 and 2008 [9]. Abstinence-only sex education continues to be funded by the federal government, for example, in fiscal year 2014 the Title V State Abstinence Education Grant Program granted \$35.8 million to 39 States and Territories serving nearly 300,000 youth [10]. When the Bush Administration increased federal funding for abstinence-only education to unprecedented levels, for the first time the federal government became highly involved in the funding of sex education, including the Community Based Abstinence Education program (CBAE), and debates began to play out on the floor of Congress. We study this moment in time in order to understand how contested meanings about gender functioned in the initial policy adoption and implementation processes.

During this time debates over sex education were largely-dichotomized between abstinence-only and comprehensive sex education proponents. Outwardly, sex education debates revolved around the issue of program efficacy — both sides argued that their approach is better at delaying the initiation of sex, encouraging returns to abstinence, reducing the number of sexual partners, and decreasing the frequency of sex among teens. Comprehensive sex education proponents claimed that their programs increase the rates of correct and consistent contraceptive use among sexually active youth and that withholding information about contraception and disease prevention leaves teens ill-prepared to protect themselves, placing them at higher risks for pregnancy and STDs/HIV transmission [11]. AOE supporters believed that comprehensive sex education programs "implicitly condone sexual activity among teen" and that providing teenagers with information about contraception increases their levels of sexual activity, promiscuity, pregnancy, and disease [12]. Empirical research of program efficacy overwhelming weighed on the comprehensive side of the sex education debate [11]. Despite the fact that research unequivocally supports comprehensive over abstinence approaches, the debate over sex education persists, and more should be done to link scientific findings to sex education programs [13]. Kristin Luker argues that local sex education controversies are primarily about intrinsic value differences about gender, sex, marriage, and family, and that these value differences, not efficacy concerns, drive the sex education debates [7]. The broader content of sex education programs is important. Michelle Fine documents a missing discourse of desire in early sex education programs while Jocelyn Boryczka finds that abstinence-only programs promote an individual notion of personal responsibility rather than a more collective ideal [14] [15]. We contribute to knowledge of sex education implementation on the local level by studying how federal-level sex education debates play out on the floor of Congress and how these debates compare to the content of the programs implemented through federal funding.

\section{Methods and Data}

We perform a critical discourse analysis of federally-funded abstinence-only curricula and the congressional 
policy debates that spurred their development and implementation [2]. We employ a grounded theory methodology to facilitate the work of interpretive policy research in uncovering "how policy means" [4] [16].

We analyze three of the most commonly used abstinence-only curricula implemented in public schools across the United States which were funded by the CBAE program: Choosing the Best Soul Mate, published by Choosing the BEST and targeted at grades 11 and 12; Me, My World, My Future, published by Teen-Aid with a target audience of low-income high school students; and WAIT (Why Am I Tempted), published by WAIT Training for junior high and high school students. The curricula range in length from approximately 75 to 400 pages and consist of six to twenty lesson plans, teacher scripts, and educational materials for students such as inclass handouts, homework, and tests.

We analyze two debates in the House of Representatives during the $107^{\text {th }}$ Congress which contained abstinence-only education components: one which focused on appropriations for the Community Based Abstinence Education program (CBAE) and one which addressed abstinence-only education in the context of welfare reauthorization. The October 11, 2001 House floor debate of H.R. 3061, the Departments of Labor, Health and Human Services, and Education, and Related Agencies Appropriations Act of 2002 ultimately appropriated \$40 million in CBAE abstinence-only funding, \$10 million over the President's budget request. The May 16, 2002 House floor debate of H.R. 4737, the Personal Responsibility, Work and Family Promotion Act of 2002, would have reauthorized TANF, the program created by the 1996 welfare reform including the abstinence-only education components. The bill passed the House but not the Senate. TANF and the related abstinence-only education programs were eventually reauthorized by the Deficit Reduction Act of 2005.

\section{Analysis}

\subsection{Abstinence-Only Curricula}

Abstinence-only curricula overtly, actively teach and celebrate gender difference. They teach that men and women are fundamentally oppositional beings with disparate needs, desires, and motivations; women are passive, relational, and relatively unsexual, while men are aggressive, detached, and hypersexual. In addition, the contents of the abstinence-only curricula are entirely heteronormative.

While all abstinence-only curricula celebrate gender difference, the WAIT Training curriculum contains the most overt lessons on gender difference of the three programs we studied. Lesson Four in the curriculum is entitled "The Differences between Men and Women”, and it begins with the following introduction:

Let's face it, men and women are different. Not just in terms of anatomy, but even in the ways they typically think and act in various situations. While the nature vs. nurture debate is likely to rage on for centuries, it's clear that men and women are not the same. We don't easily understand one another, but if the runaway success of the book Men Are From Mars, Women Are From Venus is any indication, we desperately want to... As this curriculum was being developed, we asked teens what they wanted to know. Girls wanted to understand why guys say they're going to call, and then don't call. Guys wanted to know why girls flirt and tease when they have no intentions of pursuing a physical relationship... This unit is designed to cover these types of questions and explore the differences between men and women so that teens have the information needed to pursue healthier, more satisfying relationships with the opposite sex [17].

The objective of the lesson above is "To teach teens the research regarding the differences between men and women and to foster understanding, appreciation, and communication between the genders".

The abstinence-only curricula teach that gender difference is a taken-for-granted part of life. "Let's face it, men and women are just different," the reasoning goes. "Guys say they're going to call, and then don't", while "girls flirt and tease when they have no intentions of pursing a physical relationship". The message is clear: young men are emotionally unavailable and only interested in unattached sex, while young women are interested in relationships and use sexiness (not necessarily sex) in order to lure men to them. Additionally, the curricula teach that if students recognize and uphold these differences, they will have "healthier, more satisfying relationships with the opposite sex".

Immediately following the above lesson on gender difference, WAIT Training teaches students a long list of seemingly benign (and often untrue) anecdotes that have nothing to do with sex, relationships, or reproduction in order to underscore the lesson that women and men are inherently different beings.

Say, "How about this: Without a backpack, how do guys carry their books? (demonstrate books under your 
arm). How do girls carry them? (demonstrate against your chest). No one had to teach you that, right? It's an innatebehavior [17].”

Surely human beings are not born with natural, gendered book-carrying techniques, but the curriculum lists numerous such examples to naturalize the message that women and men are different, including the ways in which they look at their fingernails or at the bottom of their shoes. The angle from which one carries their books, gazes at their fingernails or checks their shoe bottoms is not an inborn trait, nor does it have anything to do with human reproduction or sexual health. Rather, these examples work to teach the sociobiological message that gendered humans are innately different beings.

The WAIT Training teaches students a lengthy lesson on the physiological differences between women's and men's bodies that implicitly naturalizes gender differences. The lesson includes such facts as: "Women's metabolism is usually lower than men's... Women's blood contains more water and $20 \%$ fewer red blood cells. Since red blood cells supply oxygen to body cells, women tire more easily and are more prone to faint" and "On the average, men possess 50\% more brute strength than women [17]”. Most of the physiological facts listed have little to do with sexual health, reproduction, or any of the other objectives of typical sex education programs, but the curriculum teaches and tests students on this material nonetheless. By teaching these seemingly benign facts, the curriculum sets the stage for the broader message that, like bodies, socially constructed gender differences are natural, essential, immutable truths. Further, the curriculum subtly weaves in lessons of gender inequality. It perpetuates the notion that women are physically weaker than men by saying that they are "more prone to faint" and that men possess "more brute strength than women". It also presents men as the norm by listing most of the facts in terms of how women's bodies deviate from men's bodies.

These physiological lessons also silence notions of commonality, as it offers no room for students to discuss physiological similarities among men's and women's bodies. And, in fact, the curriculum warns students against doing so. "When we fail to recognize or remember that we operate with different systems, men and women easily find themselves hurt, angry, and frustrated by the opposite sex" the curriculum states. "This can quickly deteriorate into relationship disillusion and disappointment. In order for us to live and work together better, we need to understand the unique differences of the sexes [17].” Thus, the curriculum teaches that recognizing similarity among women and men leads to pain, anger, and frustration and that students' relationships will be improved if they "understand the unique differences of the sexes". The curriculum even suggests that students who recognize gender differences are more attractive to the "opposite" sex.

WAIT Training not only teaches that gender is about difference, but also that gender difference is good, and similarity is bad. The curriculum teaches that recognizing and upholding gender difference leads to better relationships, happier lives, and better looks, and by implication then, the lesson is that those who value gender similarities are less happy, less fulfilled, and less attractive. Through its overt statements and subtle implications, the WAIT Training program silences notions of similarity among genders and cautions students against egalitarian understandings of the world. Although WAIT Training is the only curriculum that teaches a distinct lesson on gender difference, all three AOE curricula construct versions of masculinity and femininity that rest on the principles articulated in the lesson above-gender is about difference, and difference is necessary and good. Now, we turn to the differentiated constructions of masculinity and femininity in abstinence-only education, which silence notions of similarity among women and men.

\section{Femininity and Masculinity}

The abstinence-only curricula present versions of femininity and masculinity that rest on the premise that gender is about difference and that difference is good. The AOE curricula are rife with side-by-side definitions of femininity and masculinity that construct women and men as oppositional, complementary creatures. They consistently present femininity as relational, emotional, and passive and masculinity as rational, detached, and active. The following example from the Choosing the Best Soul Mate curriculum exemplifies this:

Guys

Communication Purpose: To REPORT information

Primary Emotional Needs: COMPETENCY, SELF-SUFFICIENCY

Feels Loved When: COMPETENCY is acknowledged

Feels Unloved When: CRITICIZED, rarely affirmed

Girls 
Communication Purpose: To affirm RAPPORT, while sharing information

Primary Emotional Needs: Being TOGETHER, QUALITY of RELATIONSHIP

Feels Loved When: FEELINGS are acknowledged

Feels Unloved When: Not LISTENED to, feelings not validated [18]

The curricula construct men and women as having mutually exclusive, oppositional interpersonal characteristics and needs. They present students with a caricature of masculinity and femininity in which young women are relational, dependent, emotional, and needy, while young men are detached, independent, unemotional, and autonomous. Over and over again the curricula present a world in which women are almost exclusively driven by their feelings and their need to build relationships, while men, alternatively, are driven by their interests, adventures accomplishments. The following teacher script exemplifies this point:

Say, "A researcher had 3-year-old boys in a room with toy trucks. What do you think the boys did with the trucks? Allow for the class to guess, then explain that they crashed them into each other and made boy noises and crashing sounds." Then ask, "What do you think happened when little girls were playing with the trucks?” Allow for the class to guess, then explain that they said, "Get in the truck, Honey, we're going to the doctor. It's not going to hurt.” Girls are very relational [17].

In just a few sentences, the above example encapsulates curricular constructions of women as compassionate, mature, responsible, empathetic, and nurturing, and men as independent, detached, playful, competitive, and aggressive. The AOE curricula imply that these gendered traits are innate and scientifically established, and offer little room for students to explore similarities between women and men. In the above example the invocation of young children implies that difference is present from childhood (or perhaps even birth), and is therefore likely unchangeable. The phrase "boy noises" makes it seem as if children naturally make gendered sounds. Furthermore, the passage's summoning of the "researcher" gives it scientific authority.

Since "girls are very relational" in the AOE curricula, women's wellbeing is tied to male romantic partners. Conversely, men are autonomous and independent, and their wellbeing is independent of their romantic relationships. These messages are reinforced in the Choosing the Best Soul Mate curriculum through the stories of "The Disappointed Princess" and "The Knight in Shining Armor", which simultaneously construct women as "very relational" and needing of heterosexual relationships, and then uses this to threaten them into passivity —if you're not passive enough you will lose your main source of happiness-your boyfriend. Further, it conjures well-known stereotypes of assertive, outspoken women as obnoxious nags. These stories also teach that all men are entitled to dominance: "Deep inside every man is a knight in shining armor ready to rescue a maiden and slay a wicked dragon. When a man feels trusted and appreciated he is free to be the strong, protecting man he longs to be [18]." This statement implies that heroic masculinity and passive, docile femininity are somehow natural because these traits exist "deep inside". The story underscores the male sexual drive discourse in that it teaches that men should be the heroic, protective, "knowers" and "doers" in every situation and that women should likewise be passive objects (and if they're not, men are entitled to leave). This places an exorbitant amount of pressure on young men, who can't possibly live up to the responsibility of perpetually being heroic experts. Further, when this logic is extended to sexual scenarios, which is not too far a logical jump as this is, after all, a sex education program, it becomes even more troubling. The story constructs women's agency as emasculating and threatening, even when the stakes are high, making a situation in which women claim sexual pleasure, require safer sex, or navigate their way out of sexual assault scenarios difficult to imagine. Further, both of the aforementioned fairy tales tell of violent, aggressive, competitive knights, making the sexual assault risk seem even more possible.

As these lessons on oppositional femininity and masculinity indicate, the contents of all of the abstinenceonly curricula are overwhelmingly heteronormative. The curricula primarily reproduce heteronormativity through silence- the three programs are almost altogether mute on non-heterosexual sexualities. WAIT Training lists "no gay bashing" as one of twenty-three potential classroom norms for teachers to establish, but that is as far as the curriculum goes in addressing homosexuality. Me, My World, My Future mentions homosexuality only three times in its 373 pages, and each time it does so pathologically: the curriculum lists "sexual preference" as a potential outcome of childhood sexual abuse; it lists HIV rates in terms of "homosexual and bisexual men"; and it teaches students that AIDS infection rates are difficult to measure because the "number of homosexuals" is declining [19]. Choosing the Best, alternatively, is totally silent on homosexuality. However, it vividly displays its heteronormative underpinnings when it gives the following instructions to teachers: "SAY, 'Now I 
would like for each of you to pair up with a member of the opposite sex to go through the... exercise.' NOTE: In the event that there are an uneven number of guys and girls consider pairing two students of the same sex with one of the opposite sex [18].” Thus, the curriculum would rather students simulate polyamorous heterosexual relationships than homosexual ones.

The versions of active, detached, independent masculinity and passive, relational, dependent femininity taught in abstinence-only education rest on a foundation of difference that breeds inequality. These limiting, differentiated versions of masculinity and femininity place all young bodies and minds at risk, however young women disproportionately bear the consequences. Abstinence-only curricula teach that young women are less strong, less logical, and less independent than young men while simultaneously underscoring masculine aggression and denying young men's emotionality, thereby reifying young women's vulnerability and contributing to a culture that accepts violence against women.

\subsection{Congressional Debates}

While as implemented, abstinence-only sex education curricula actively teach gender difference, when the funding for these programs was debated on the floor of Congress the debates appeared in predominantly gender neutral framing despite the highly gendered phenomena being discussed. While the debates frequently referenced teen pregnancy, teen sexual activity, and "unwed births", gender neutral language was used to discuss these highly gendered topics. Members of Congress frequently referenced kids, teens, and young people, occasionally referenced girls and young women but never referred to boys or young men. These patterns were consistent across parties, gender of speaker, and position on abstinence-only education.

While using the same gender neutral language, Republican supporters of abstinence-only education and Democratic supporters of comprehensive sex education framed the need for sex education differently. Republicans argued that we need to teach kids self-control, show them leadership by telling them consistently what is expected and emphasize that teen sex is deadly, while Democrats argued that kids need information to protect themselves and that we should listen to teens in forming these policies.

The arguments in support of abstinence-only education often rested on the argument that sex is deadly. Representative Hostettler declared, we need to "educate kids about how sex can wait and that many of the consequences of early sexual activity are incurable and deadly" [20]. Representative Hayes concurred, arguing that through proper leadership and good examples we could protect our children.

Young people, teenagers in particular, are very, very bright. They respond to proper leadership and good examples. If we tell them that this promiscuous behavior is going to happen, they cannot make the right choices, and then offer them contraceptives which have a 20 percent failure rate, we have not done our duty. We have not protected our young people. But if we say to them, abstinence until marriage is the healthy way to100 percent provide protection from sexually transmitted diseases and unwanted pregnancies, then I say to my colleagues, we have done our job [20].

Similarly, Representative Pitts emphasized the need to teach young people "the truth” that sex outside of marriage is risky and teach them self-control.

We need to start teaching our young people the truth. Sex outside of marriage is risky business, and it has physical and emotional consequences. ...We need to stop lying to our Nation's youth and stop assuming that promiscuity is an inherent part of adolescent life. Instead, through absence education, programs which have proven to be successful, we need to promote their health and safety. We need to encourage them to exercise self-control... If we believe that children can exercise self control to avoid smoking, what about premarital sex? [20]

These supporters of abstinence-only education argued that through proper leadership, good examples, and teaching self-control we can protect young people from the dangers of sex.

Yet democratic supporters of comprehensive sex education countered that young people need information in order to make good choices. They locate danger not in sex but in a lack of truthful, scientific information. Congresswoman Maloney argued, "Abstinence-only education works only when it is combined with comprehensive sexuality education... Telling independent-minded teenagers what not to do and depriving them of information they might use to decide is a recipe for unplanned pregnancies and sexually-transmitted diseases [20]." Similarly 
in another debate, Representative Jackson-Lee intoned, "With respect to the issue of abstinence, no one opposes it, but we like to have the truth. Teenagers want to know the whole truth and nothing but the truth. This bill is limiting, and my colleagues know that this is wrong [21]."

Congresswoman Capps emphasized we should listen to teens, as she told of her experience directing a teen parent and pregnancy program in Santa Barbara.

These teen parents were the first to urge abstinence to their peers, to their younger brothers and sisters, even though they did not use the word. But their message was all about knowledge, comprehensive sex education. They did not use that term either, but they did know the power it gives when information is not based on fear or incomplete and half-truths [21].

The democratic supporters of comprehensive sex education emphasized the problem was lack of information to make good choices, and the solution was truthful, scientific information, not scare tactics.

The vast majority of the debates were articulated in gender neutral language. For example, both Representatives Hostettler and Pence cited the statistics that, "Each year, three million teens contract sexually transmitted diseases; and nearly one million become pregnant [20]." Pence added, "One-third of those pregnancies end tragically in abortion [20].” Both Republican men use gender neutral language to talk about the highly gendered condition of pregnancy.

Whether in support of or against abstinence-only funding, members of Congress framed the target population of sex education programs in gender neutral terms. Speaking in support of increasing funding for abstinenceonly education, Representative Istook declared: "The more we sent a mixed message that says it is okay to have sex out of wedlock, it is okay, kids, just be safe about it, the more we undercut what Mom and Dad tell their kids, the more we undercut what they are taught at church, the more we found that we got more of the problem [20]." Representative Maloney challenged his logic by arguing, "Evidence shows that comprehensive sexuality education helps delay sexual relations among young people, and increases contraceptive use among those who become sexually active [20]." While of different parties, genders, and policy positions, both used the same gender neutral language to make their points. In so doing, they framed the problem as one of age (focused on young people) rather than one of gender.

The link between teen pregnancy and welfare receipt was a frequent argument for government intervention, whether through abstinence-only or comprehensive sex education programs. This argument too, most often appeared in gender neutral terms, like those used by Representative Istook to advocate for increased funding for abstinence-only education:

Do Members want to fund the things that are having the first success in three decades in combating teenagers who are involved sexually, get disease, get pregnant, drop out of school, turn to alcohol, turn to drugs, do not get their education, cannot support themselves, go on public assistance, raise kids in that environment? Is that what we want?... Let us save some kids. Let us help people not get into this cycle of disease and poverty [20].

Istook remained consistently gender neutral in his language though teen girls are the ones in his tale who will get pregnant, go on public assistance, and raise kids. Congresswoman Harman also links poverty and welfare receipt to teen pregnancy, but makes the gender of these dynamics visible.

Mr. Speaker, preventing teen pregnancy is a key part of moving people from welfare to work and reducing poverty. Over half of all mothers on welfare had their first child as a teenager, and two-thirds of the families begun by teen mothers are poor. For all these reasons, preventing teen pregnancy is an issue we all should be able to agree on in Congress [21].

Indeed while couched in gender neutral terms, pregnancy and sexually transmitted diseases (STDs) have gendered consequences.

In the few instances when members of Congress explicitly gendered the abstinence-only debates, the emphasis was placed on girls and reproduction, either in the form of preventing young women from becoming pregnant or decrying the rates of Chlamydia infections among teen girls, which may have consequences for future reproduction in adulthood. Though he frequently spoke of pregnancy with gender neutral language, in one speech Representative Pence made the gender of this phenomenon visible.

Here in Washington, D.C. where 15 percent of girls become sexually active in the eighth grade, according 
to statistics, there is a program known as the Best Friends Foundation, which has reduced that number to 5 percent in real terms. In the District of Columbia, 27 percent of girls age 15 to 19 become pregnant each year, but among the Best Friends girls in that age range, only 2.5 percent have ever become pregnant [20].

In one other instance, Representative Hall specifically mentioned young women as the ones who get pregnant:

Teen pregnancy is a problem that affects the entire country, not just the young women who are forced to make the difficult decisions at an early age. The number of teen pregnancies and sexually transmitted diseases continues to increase despite the number of family planning style sex education programs that have been offered [21].

Hall highlights the gendered nature of pregnancy in order to argue that teen pregnancy should not be viewed as just the problem of young women. In so doing, he calls into question the gender neutrality of all other references to teen pregnancy.

In addition to occasionally referencing gender with regard to pregnancy, gender was made visible once in debates about teenage rates of sexually transmitted infections. "Young women often do not find out until they reach their childbearing years they are not able to have kids now because they got involved in teenage sex, they got chlamydia, now they cannot have kids [20].” All other points about teen rates of sexually transmitted diseases were made in gender neutral terms. Here again in highlighting the differential effects of some diseases for men and women, Istook shows how his previously gender neutral framing is in fact false, given the gendered nature of sex, pregnancy, and sexually transmitted diseases.

Importantly the gendered nature of teenage sexual activity was never made visible through references to boys or young men. Not one male-focused statistic was cited. Not one example highlighted the consequences or responsibilities of sex for boys. To the extent that these debates were explicitly gendered, only women were constructed as having gender. Yet one could also argue that women were in fact the target of much of the gender neutral framing in the debates. "Teen pregnancy" can only be understood has happening in the body of a young woman. This pregnancy might have been conceived through sex with a teenage boy or through sex with an adult male, but what makes it a teen pregnancy is that it occurs in the gendered body of a teenage girl.

As the analysis of the curricula indicates, gender is not only a question of effects for boys versus girls, but is also a set for norms and expected behaviors. Gender in this sense was all but invisible in the congressional debates. Beyond the question of abstinence versus comprehensive programs, there was no debate about the specific content of sex education programs, certainly not the gendered messages. The one exception was Congresswoman Capps, who herself directed a teen parent and pregnancy program in Santa Barbara.

Unfortunately, some of these abstinence-only programs use terror tactics to try to keep teens from having sex, they exaggerate the failure rates of condoms, and some federally funded programs denigrate women, suggesting that they are not as smart or as capable as men [21].

This is the only moment in the $107^{\text {th }}$ Congress where the gendered messages of abstinence-only curricula were made visible. As the analysis of the curricula reveals, gendered messages are a central component of abstinence-only sex education curricula.

\section{Findings}

\subsection{Neutrality Debated, Difference Implemented}

Abstinence-only curricula teach the message that gender is about difference, and that difference is necessary and good. The curricula teach students oppositional versions of femininity and masculinity in which femininity is emotional, passive, and relational and masculinity, its complement, is logical, aggressive, and detached. These versions of femininity and masculinity silence similarities among people, as they discourage students from thinking about how most people, regardless of gender, sexual orientation, or gender identity, require similar things such as respect, love, and communication.

Yet the congressional debates which authorized funding for these curricula took place in gender neutral terms. The gender neutral terms "teens" and "young people" were used frequently. On a few occasions teen girls were specifically mentioned in relationship to pregnancy or STDs like Chlamydia. There was no mention of teaching gender as an important component of AOE curricula, only a debate on whether to teach abstinence alone or to teach also information on disease prevention and contraception. Yet our analysis shows that teaching normative 
gender roles is central to these curricula. This focus was all but absent from the congressional debates which funded the programs, with the single exception of Representative Capps who wisely raised the concern that "some federally funded programs denigrate women, suggesting that they are not as smart or as capable as men" [21].

\subsection{Gendering across the Policy Process}

In the case of abstinence-only sex education, the State directly funds the teaching of gender difference while using gender neutrality to justify it. This disconnection between the gender neutrality of the congressional debates and the highly gendered lessons of the curricula raises important question for how gender functions across the policy process. The gender neutrality of the congressional framing and the focus on the efficacy of abstinence-only versus comprehensive sex education in the debates leave not interrogating the gendered messages of the programs. The argument of "what works", abstinence or comprehension, is not enough; we need to pay attention to how it works, especially with regard to the teaching of gender inequality.

\section{Acknowledgements}

We gratefully acknowledge comments on an earlier version of this article from the panel participants and discussant, Jodi Dean, at the Western Political Science Association in 2011.

\section{References}

[1] Bacchi, C. (1999) Women, Policy and Politics: the Construction of Policy Problems. Sage, London.

[2] Yanow, D. and Schwartz-Shea, P., Eds. (2006) Interpretation and Method: Empirical Research Methods and the Interpretive Turn. M.E. Sharpe, Armonk.

[3] Schneider, A. and Ingram, H. (2008) Social Constructions in the Study of Public Policy. In: Holstein, J. and Gubrium, J., Eds., Handbook of Constructionist Research, Guilford Publications, New York, 189-212.

[4] Yanow, D. (1996) How Does a Policy Mean? Interpreting Policy and Organizational Actions. Georgetown University Press, Washington DC.

[5] Moran, J.P. (2000) Teaching Sex: The Shaping of Adolescence in the 20th Century. Harvard University Press, Cambridge.

[6] Irvine, J. (2002) Talk about Sex: The Battles over Sex Education in the United States. University of California Press, Berkeley.

[7] Luker, K. (2006) When Sex Goes to School: Warring Views on Sex—and Sex Education—Since the Sixties. W. W. Norton \& Company, New York.

[8] Doan, A. and Williams, J. (2008) The Politics of Virginity: Abstinence in Sex Education. Praeger Publishers, Westport.

[9] Advocates for Youth (2007) The History of Federal Abstinence-Only Funding. http://www.advocatesforyouth.org/storage/advfy/documents/fshistoryabonly.pdf

[10] Family and Youth Services Bureau (2015) State Abstinence Education Grant Program Fact Sheet. Administration for Children and Families, Washington DC. http://www.acf.hhs.gov/programs/fysb/resource/aegp-fact-sheet

[11] Kirby, D. (2008) The Impact of Abstinence and Comprehensive Sex and STD/HIV Education Programs on Adolescent Sexual Behavior. Sexuality Research \& Social Policy, 5, 18-27. http://dx.doi.org/10.1525/srsp.2008.5.3.18

[12] Rector, R. (2002) The Effectiveness of Abstinence Education Programs in Reducing Sexual Activity Among Youth. Heritage Foundation, Washington DC. http://www.heritage.org/Research/Abstinence/BG1533.cfm

[13] Schalet, A., et al. (2014) Broadening the Evidence for Adolescent Sexual and Reproductive Health and Education in the United States. Journal of Youth and Adolescence, 43, 1595-1610. http://dx.doi.org/10.1007/s10964-014-0178-8

[14] Fine, M. (1988) Sexuality, Schooling, and Adolescent Females: The Missing Discourse of Desire. Harvard Educational Review, 58, 29-53. http://dx.doi.org/10.17763/haer.58.1.u0468k1v2n2n8242

[15] Boryczka, J. (2009) Who Cares? Privileged Irresponsibility \& Sex Education Policy. Politics \& Gender, 5, 1-26. http://dx.doi.org/10.1017/S1743923X09000154

[16] Charmaz, K. (2006) Constructing Grounded Theory: A Practical Guide through Qualitative Analysis. Sage, London.

[17] WAIT Training (2003) WAIT Training. 2nd Edition, Greenwood Village, Colorado.

[18] Choosing the Best (2004) Choosing the Best Soul Mate. Choosing the Best Publishing, Atlanta.

[19] Teen-AID (1993) Me, My World, My Future. 2nd Edition, Teen-Aid, Inc., Spokane. 
[20] US Congress (2001) Departments of Labor, Health and Human Services, and Education, and Related Agencies Appropriations Act 2002. Congressional Record, 147, H6667-H6672.

http://www.gpo.gov/fdsys/pkg/CREC-2001-10-11/pdf/CREC-2001-10-11-pt1-PgH6569-2.pdf

[21] US Congress (2002) Personal Responsibility, Work, and Family Promotion Act of 2002. Congressional Record, 148, H2549-H2552. http://www.gpo.gov/fdsys/pkg/CREC-2002-05-16/pdf/CREC-2002-05-16-pt1-PgH2517-5.pdf 